\title{
Penerapan Teori Belajar Van Hiele Berbantuan Geogebra untuk Meningkatkan Kemampuan Penalaran Matematis Siswa
}

\author{
Hedi Budiman ${ }^{1, *}$, Mia Rosmiati \\ ${ }^{1,2}$ Universitas Suryakancana \\ *hedi@unsur.ac.id
}

\begin{tabular}{|l|l|l|} 
Received : $18-2-2020$ & Revised: $25-3-2020$ & Accepted: $1-4-2020$
\end{tabular}

\begin{abstract}
ABSTRAK
Teori belajar Van Hiele menjelaskan tingkatan berpikir anak dalam memahami konsep geometri. Penggunaan GeoGebra dalam penerapan teori belajar Van Hiele untuk membantu siswa dalam memahami konsep-konsep geometri. Penelitian ini bertujuan untuk mengkaji peningkatan kemampuan penalaran matematis siswa dengan menggunakan penerapan teori belajar Van Hiele berbantuan Geogebra.Penelitian ini menggunakan metode kuasi eksperimen dengan desain penelitian Pretest and Postest Group. Populasi pada penelitian ini adalah siswa SMP kelas VIII di Kabupaten Cianjur. Pemilihan sampel dilakukan dengan purposive sampling. Hasil penelitian menunjukan bahwa kemampuan penalaran matematis siswa yang mendapat pembelajaran dengan penerapan teori belajar Van Hiele berbantuan Geogebra lebih baik daripada kemampuan penalaran matematis siswa yang mendapat pembelajaran ekspositori. Rata-rata peningkatan kemampuan penalaran matematis kelas eksperimen lebih tinggi daripada kelas kontrol. Sikap siswa positif terhadap penerapan teori belajar Van Hiele berbantuan Geogebra
\end{abstract}

Kata Kunci: Penalaran Matematis, Teori Belajar Van Hiele, GeoGebra

\section{ABSTRACT}

Van Hiele's learning theory explains the level of thinking of children in understanding the concept of geometry. The use of GeoGebra in the application of Van Hiele's learning theory to assist students in understanding geometrical concepts. The research aims to examine the improvement of students' mathematical reasoning abilities by using the application of Geogebra-assisted Van Hiele learning theory. The research used a quasi-experimental method with Pretest and Postest Group research designs. The population in this study was eighth grade junior high school students in Cianjur Regency. The sample selection is done by purposive sampling. The results showed that the mathematical reasoning ability of students who got learning by applying Geogebra-assisted Van Hiele learning theory was better than the mathematical reasoning ability of students who got expository learning. The average increase in mathematical reasoning ability of the experimental class is higher than the control class. The attitude of students is positive towards the application of Van Hiele's learning theory assisted by Geogebra

Keywords: Mathematical Reasoning, Van Hiele's Learning Theory, GeoGebra

\section{PENDAHULUAN}

Kemampuan penalaran matematis (Mathematical Reasoning) merupakan suatu kemampuan dalam memberikan penjelasan dan menarik kesimpulan yang logis berdasarkan fakta-fakta, sifat, dan hubungan yang diketahui serta dapat mengembangkan 
pola dan hubungan untuk menganalisis situasi matematis (Monariska, 2018; Muhammad, 2017; Salmina \& Nisa, 2018; Tina Sri Sumartini, 2015). Terdapat kesalahan siswa yang berbeda dilihat dari peringkat sekolah dalam melakukan pemahaman dan penalaran matematis antara lain kesalahan pada pemahaman instrumental paling banyak dialami siswa dari sekolah peringkat rendah, kesalahan pemahaman rasional dari sekolah peringkat rendah dan sedang, kesalahan penalaran induktif dari sekolah peringkat rendah dan penalaran deduktif dari sekolah peringkat rendah dan sedang.

Selanjutnya, bahwa kesalahan yang dilakukan siswa sekolah menengah dalam mengerjakan soal-soal matematika dikarenakan kurangnya kemampuan penalaran terhadap kaidah dasar matematika. Rendahnya kemampuan penalaran dapat dilihat dari hasil tes yang dilakukan oleh PISA (Programme for International Student Assessment) tahun 2012 dengan mengukur kecakapan anak-anak usia 15 tahun dalam mengimplementasikan masalah-masalah di kehidupan nyata melalui tes yang meliputi kemampuan matematis, membaca dan ilmu pengetahuan umum. Hasil dari tes ini pun cukup mengejutkan, yaitu Indonesia menempati peringkat ke-64 dari 65 negara yang berpartisipasi dalam tes. Indonesia hanya sedikit lebih baik dari Peru yang berada di peringkat terbawah (Zyngier et al., 2013).

Memperhatikan kondisi tersebut mengembangkan dan membelajarkan kemampuan penalaran matematis kepada siswa menjadi sangat penting yang harus diperhatikan oleh guru. Guru juga harus dapat memberikan kesempatan dan memfasilitasi siswa agar dapat mengembangkan kemampuan matematis, khususnya kemampuan dalam bernalar. Hal ini didukung dengan dicanangkannya kurikulum terbaru yaitu kurikulum 2013 yang dalam pelaksanaan pembelajarannya yaitu menggunakan pendekatan saintifik, sehingga memudahkan guru agar siswa lebih aktif menemukan sendiri konsep-konsep matematis, menyelesaikan masalah penalaran matematis, dan lain sebagainya, tentunya dengan stimulus-stimulus yang diberikan guru pada saat pembelajaran (Maskur et al., 2020).

Dari beberapa hasil penelitian yang telah dilakukan mengenai kemampuan penalaran matematis, salah satunya oleh (Komala \& Rismayanti, 2017) yang hasilnya menyatakan bahwa peningkatan kemampuan penalaran matematis siswa yang memperoleh pendekatan explicit instruction dengan teknik scaffolding lebih baik daripada siswa yang memperoleh pembelajaran biasa.

Hasil penelitian tersebut menunjukan bahwa membelajarkan matematika kepada siswa, guru harus kreatif mencari dan menemukan metode atau model yang dapat digunakan untuk pembelajaran matematika khususnya agar siswa dapat bernalar secara 
matematis, dalam arti siswa harus mampu berpikir logis yang menggunakan logika induksi dan deduksi untuk menghasilkan suatu kesimpulan atau penyelesaian suatu masalah. Salah satu materi matematika yang memiliki karakteristik tersebut adalah geometri.

Geometri sebagai salah satu bidang kajian dalam materi matematika sekolah memperoleh porsi yang besar untuk dipelajari oleh siswa di sekolah. Namun demikian penguasaan siswa dalam memahami konsep geometri masih rendah dan perlu ditingkatkan. Seperti yang dituturkan oleh (Nanang Supriadi, 2015) bahwa salah satu bagian dari matematika yang sangat lemah diserap oleh siswa di sekolah adalah geometri. Untuk memfasilitasi pembelajaran geometri yang lebih baik, penulis mengangkat sebuah teori belajar yaitu teori belajar Van Hiele sebagai salah satu perencanaan untuk meningkatkan kemampuan penalaran matematis siswa.

Teori belajar yang dikemukakan oleh Van Hiele menguraikan tahap-tahap perkembangan mental anak didik dalam bidang geometri, Pemilihan teori belajar Van Hiele sebagai dasar pembelajaran dalam mengembangkan kemampuan penalaran matematis siswa memiliki alasan sebagai berikut:

1. Teori belajar Van Hiele fokus pada pembelajaran geometri.

2. Dalam teori belajar Van Hiele terdapat beberapa tingkatan (hierarkis) pemahaman dalam belajar geometri, dimana setiap tingkat mempunyai tingkatan berpikir yang dapat membantu siswa dalam memahami konsep geometri.

Walle (2008) mengemukakan beberapa tingkatan pemikiran geometris Van Hiele, yaitu Level 0 (Visualisasi), Level 1 (Analisis), Level 2 (Deduksi Formal), Level 3 (Deduksi), Level 4 (Ketepatan/Rigor).

Beberapa orang yang telah melakukan penelitian tentang teori belajar Van Hiele seperti (Suherman, 2016) yang menyebutkan bahwa peningkatan kemampuan pemahaman geomteri siswa yang mendapatkan model pembelajaran Van Hiele lebih tinggi daripada siswa yang mendapatkan pembelajaran konvensional. Hal tersebut disebabkan karena konsep dalam matematika khususnya bidang kajian geometri memang abstrak, sedangkan umumnya siswa berpikir dari hal-hal yang konkret menuju hal yang abstrak, maka salah satu jembatanya agar siswa mampu berpikir abstrak tentang matematika, adalah dengan menggunakan metode atau model-model yang sesuai serta media belajar dan alat peraga yang dapat menunjang dan mempermudah dalam proses pembelajaran.

Seiring dengan perkembangan zaman yang begitu pesat media dan alat peraga dalam pembelajaran matematika pun menjadi semakin beragam, sehingga dapat memudahkan siswa dalam pemahami konsep-konsep yang abstrak dan juga memudahkan 
guru dalam penyajian materi dikelas (Septian, 2017; Septian \& Komala, 2019; Zengin, Furkan, \& Kutluca, 2012). Pengembangan teknologi komputer selanjutnya melibatkan salah satu dynamic geometry software salah satunya yaitu GeoGebra. Software Geogebra memungkinkan visualisasi sederhana dari konsep geometris yang rumit dan membantu meningkatkan kemampuan penalaran matematis siswa.

\section{METODE PENELITIAN}

Metode yang digunakan dalam penelitian ini adalah penelitian eksperimen. Penelitian eksperimen (eksperimental research) sangat sesuai untuk menguji hipotesis tertentu yang dimaksudkan untuk mengetahui hubungan sebab akibat suatu variabel penelitian. Dalam penelitian eksperimen terdapat dua variabel yaitu variabel bebas dan variabel terikat. Variabel bebas sengaja dimanipulasi oleh peneliti, sedangkan variabel yang diamati atau diukur sebagai akibat dari manipulasi variabel bebas disebut variabel terikat.

Pada penelitian ini terdapat dua kelompok, yaitu kelompok eksperimen dan kelompok kontrol. Kelompok eksperimen dalam penelitian ini adalah kelas yang mendapatkan pembelajaran dengan menerapkan teori belajar Van Hiele berbantuan Geogebra dan kelompok kontrolnya adalah kelas yang mendapatkan pembelajaran dengan menggunakan pembelajaran ekspositori.

Pelaksanaan penelitian ini memerlukan konsep dan variabel yang jelas serta pengukuran yang cermat, karena dalam penelitian ini diberikan suatu perlakuan untuk mengetahui antara perlakuan dengan aspek tertentu yang akan diukur. Perlakuan yang diberikan dalam penelitian ini yaitu pembelajaran dengan menerapkan teori belajar Van Hiele berbantuan Geogebra dan aspek yang akan diukurnya yaitu kemampuan penalaran matematis. Oleh karena itu, variabel bebas atau variabel $\mathrm{X}$ dalam penelitian ini adalah pembelajaran dengan menerapkan teori belajar Van Hiele berbantuan Geogebra dan variabel terikat atau variabel $\mathrm{Y}$ adalah kemampuan penalaran matematis.

Desain yang digunakan dalam penelitian ini yaitu desain kelompok control pretest - posttest. Kelompok pertama sebagai eksperimen dan kelompok kedua sebagai kelompok control. Kelompok eksperimen menerapkan teori belajar Van Hiele berbantuan Geogebra, sedangkan kelas kontrol menggunakan model pembelajaran ekspositori. Adapun desain penelitiannya yaitu sebagai berikut : 


\begin{tabular}{ccc}
$\mathrm{O}_{1}$ & $\mathrm{X}_{1}$ & $\mathrm{O}_{2}$ \\
\hline $\mathrm{O}_{1}$ & - & $\mathrm{O}_{2}$
\end{tabular}

Keterangan :

$\mathrm{O}_{1}$ : Pretest

$\mathrm{O}_{2}:$ Posttest

$\mathrm{X}_{1}$ : Perlakuan dengan menerapkan teori belajar Van Hiele berbantuan Geogebra.

Penelitian ini adalah untuk melihat sejauh mana penerapan teori pembelajaran Van Hiele belajar siswa. Untuk dapat mendapatkan data tersebut diperlukan instrumen pengumpul data yang berupa tes awal dan tes akhir. Tes awal diberikan untuk mengukur kemampuan awal kelompok eksperimen dan kelompok kontrol. Sedangkan tes akhir diberikan untuk melihat kemajuan atau peningkatan belajar kedua kelompok. Tipe tes yang digunakan adalah tipe tes uraian.

Instrumen lain sebagai pendukung penelitian ini, yaitu untuk mengetahui respon siswa terhadap penerapan teori Belajar Van Hiele berbantuan Geogebra, maka diperlukan angket dan jurnal harian yang cukup diperuntukan bagi kelompok eksperimen.

\section{HASIL DAN PEMBAHASAN}

Data yang diperoleh dari penelitian ini kemudian dianalisis untuk menjawab semua permasalahan yang telah dirumuskan di bab 1 yaitu: untuk mengetahui apakah penerapan teori belajar Van Hiele berbantuan Geogebra lebih baik daripada menggunakan pendekatan pembelajaran ekspositori dalam meningkatkan keamampuan penalaran matematis serta bagaimana sikap siswa terhadap pembelajaran yang menerapkan teori belajar Van Hiele berbantuan geogebra. Analisis data meliputi analisis statistik deskriptif dan inferensial.

Berikut adalah hasil analisis statistik deskriptif data skor pretes kelas eksperimen dan kontrol dengan menggunakan bantuan software IBM SPSS Statistic versi 20. Tabel 1. Statistik Deskriptif Skor Pretes Kelas Eksperimen dan Kontrol

\begin{tabular}{ccccccc}
\hline Kelas & N & $\begin{array}{c}\text { Skor } \\
\text { Ideal }\end{array}$ & $\begin{array}{c}\text { Skor } \\
\text { Terendah }\end{array}$ & $\begin{array}{c}\text { Skor } \\
\text { Tertinggi }\end{array}$ & $\begin{array}{c}\text { Rata- } \\
\text { rata }\end{array}$ & $\begin{array}{c}\text { Standar } \\
\text { Deviasi }\end{array}$ \\
\hline Eksperimen & 27 & 24 & 1 & 5 & 3,41 & 1,047 \\
Kontrol & 28 & 24 & 1 & 5 & 3,39 & 1,031 \\
\hline
\end{tabular}

Berdasarkan Tabel 1 tampak bahwa rata-rata skor pretes kelas eksperimen adalah 3,41 dengan standar deviasi 1,047, sedangkan kelas kontrol diperoleh rata-rata 3,39 dengan standar deviasi 1,031. Angka tersebut menunjukan bahwa nilai rata-rata pretes kelas eksperimen dan kelas kontrol hampir setara dengan selisih sebesar 0,02, dan dilihat dari 
standar deviasi penyebaran kemampuan awal penalaran matematis kelas eksperimen lebih menyebar dibandingkan dengan kelas kontrol.

Pada uji normalitas, uji homogenitas dan uji kesamaan dua rata-rata menunjukkan data berdistribusi tidak normal.

Tabel 2. Hasil Uji Normalitas Data Pretes

\begin{tabular}{ccc}
\hline \multirow{2}{*}{ Kelas } & \multicolumn{2}{c}{ Kolmogorov-Smirnov } \\
\cline { 2 - 3 } & Signifikansi & Keterangan \\
\hline Eksperimen & 0,001 & Berdistribusi Tidak Normal \\
Kontrol & 0,014 & Berdistribusi Tidak Normal \\
\hline
\end{tabular}

Dilihat dari hasil uji normalitas data pretes yang tedapat pada Tabel 2 diatas diperoleh nilai signifikansi 0,001 pada kelas eksperimen dan 0,014 pada kelas kontrol. Karena nilai signifikansi pada kedua kelas tersebut lebih kecil dari 0,05, sehingga data keduan kelas tersebut berasal dari populasi yang berdistribusi tidak normal.

Tabel 3. Hasil Uji Mann Whitney Data Pretes

\begin{tabular}{cl}
\hline Asymp. Sig. (2-tailed) & Keterangan \\
\hline 0,839 & $\mathrm{H}_{0}$ diterima \\
\hline
\end{tabular}

Dari hasil uji Mann Whitney yang terdapat pada Tabel 3, diperoleh nilai signifikansi 0,839. Nilai tersebut lebih besar dari 0,05, maka $\mathrm{H}_{0}$ diterima. Dengan demikian dapat disimpulkan bahwa kedua kelas mempunyai kemampuan awal penalaran matematis yang setara. Setelah mengetahui kemampuan awal penalaran matematis siswa, selanjutnya dilakukan uji statistik deskriptif dan inferensial untuk mengetahui kemampuan akhir penalaran matematis siswa, berikut adalah hasil uji statistik deskriptif data postes.

Tabel 4. Statistik Deskriptif Skor Postes Kelas Eksperimen dan Kontrol

\begin{tabular}{ccccccc}
\hline Kelas & N & $\begin{array}{c}\text { Skor } \\
\text { Ideal }\end{array}$ & $\begin{array}{c}\text { Skor } \\
\text { Terendah }\end{array}$ & $\begin{array}{c}\text { Skor } \\
\text { Tertinggi }\end{array}$ & $\begin{array}{c}\text { Rata- } \\
\text { rata }\end{array}$ & $\begin{array}{c}\text { Standar } \\
\text { Deviasi }\end{array}$ \\
\hline Eksperimen & 27 & 24 & 5 & 24 & 16,63 & 5,692 \\
Kontrol & 28 & 24 & 7 & 23 & 13,04 & 3,746 \\
\hline
\end{tabular}

Berdasarkan Tabel 4 rata-rata skor postes kelas eksperimen adalah 16,63 dengan standar deviasi 5,692, sedangkan kelas kontrol diperoleh rata-rata 13,04 dengan standar deviasi 3,746. Angka tersebut memperlihatkan bahwa nilai rata-rata postes kelas eksperimen lebih besar daripada kelas kontrol, dan penyebaran kemampuan penalaran matematis setelah adanya pembelajaran, kelas eksperimen lebih menyebar daripada kelas kontrol karena standar deviasi kelas eksperimen terlihat lebih besar.

Untuk mengetahui ada atau tidaknya perbedaan kemampuan penalaran matematis pada kedua kelas tersebut dilakukan analisis uji statistik data postes, dengan terlebih 
dahulu dilakukan uji normalitas distribusi populasi, uji homogenitas varians dan uji perbedaan dua rata-rata.

Tabel 5. Hasil Uji Normalitas Data Postes

\begin{tabular}{ccc}
\hline \multirow{2}{*}{ Kelas } & \multicolumn{2}{c}{ Kolmogorov-Smirnov } \\
\cline { 2 - 3 } & Signifikansi & Keterangan \\
\hline Eksperimen & 0,048 & Tidak Berdistribusi Normal \\
Kontrol & 0,117 & Berdistribusi Normal \\
\hline
\end{tabular}

Dari hasil uji tersebut dilakukan uji statistik selanjutnya yaitu uji non parametrik menggunakan Mann Whitney dengan bantuan software IBM SPSS versi 20. Adapun hasil uji Mann Whitney data postes disajikan dalam tabel berikut ini.

Tabel 6. Hasil Uji Kesamaan Dua Rata-rata Independen Data Postes

\begin{tabular}{cc}
\hline Asymp. Sig. (2-tailed) & Keterangan \\
\hline 0,014 & $\mathrm{H}_{0}$ ditolak \\
\hline
\end{tabular}

Dari hasil uji kesamaan dua rata-rata independen yang terdapat pada Tabel 6, diperoleh nilai signifikansi 0,014. Nilai tersebut lebih kecil dari 0,05, maka $\mathrm{H}_{0}$ ditolak. Dengan demikian dapat disimpulkan bahwa kemampuan penalaran matematis siswa kelas eksperimen berbeda dengan kelas kontrol, dan dilihat dari Tabel 4 rata-rata nilai postes kelas eksperimen lebih tinggi daripada kelas kontrol. Untuk melihat peningkatannya maka dilakukan analisis data indeks gain.

Tabel 7. Statistik Deskriptif Data Indeks Gain

\begin{tabular}{cccccc}
\hline Kelas & N & $\begin{array}{c}\text { Skor } \\
\text { Terendah }\end{array}$ & $\begin{array}{c}\text { Skor } \\
\text { Tertinggi }\end{array}$ & $\begin{array}{c}\text { Rata- } \\
\text { rata }\end{array}$ & $\begin{array}{c}\text { Standar } \\
\text { Deviasi }\end{array}$ \\
\hline Eksperimen & 27 & 0,17 & 1,00 & 0,6463 & 0,27013 \\
Kontrol & 28 & 0,19 & 0,95 & 0,4700 & 0,17565 \\
\hline
\end{tabular}

Berdasarkan Tabel 7 tampak bahwa rata-rata skor indeks gain kelas eksperimen adalah 0,6463 dengan standar deviasi 0,27013, sedangkan kelas kontrol diperoleh rata-rata 0,4700 dengan standar deviasi 0,17565. Angka tersebut memperlihatkan bahwa rata-rata skor indeks gain kelas eksperimen lebih besar daripada rata-rata kelas kontrol.

Untuk melihat peningakatan masing-masing kelas dan jumlah siswa yang mengalami peningkatan kemampuan penalaran matematis dengan interpretasi kualitas peningkatanya, maka dapat dilihat pada tabel berikut ini.

Tabel 8. Statistik Deskriptif Data Indeks Gain

\begin{tabular}{ccccccc}
\hline \multirow{2}{*}{ Indeks Gain } & \multicolumn{3}{c}{ Kelas Eksperimen } & \multicolumn{3}{c}{ Kelas Kontrol } \\
\cline { 2 - 6 } & $\mathrm{Jml}$ & Interpretasi & Persentase & Jml & Interpretasi & Persentase \\
\hline $\mathrm{g} \geq 0,70$ & 10 & Tinggi & $37 \%$ & 3 & Tinggi & $11 \%$ \\
\hline $0,30<\mathrm{g}<0,70$ & \multirow{2}{*}{14} & Sedang & $52 \%$ & 20 & Sedang & $71 \%$ \\
\hline $\mathrm{G}<0,30$ & 3 & Rendah & $11 \%$ & 5 & Rendah & $18 \%$ \\
\hline
\end{tabular}


Uji statistik selanjutnya yaitu dengan uji perbedaan dua rata-rata menggunakan independent sample T'-Test dengan bantuan SPSS versi 20. Hasil pengolahan data uji perbedaan dua rata-rata independen indeks gain disajikan pada tabel berikut.

Tabel 9. Hasil Uji Perbedaan Dua Rata-rata Independen Data Indeks Gain

\begin{tabular}{cc}
\hline Setengah Nilai Asymp. Sig. (2-tailed) & Keterangan \\
\hline 0,003 & $\mathrm{H}_{0}$ ditolak \\
\hline
\end{tabular}

Dari hasil uji perbedaan dua rata-rata data indeks gain yang terdapat pada Tabel 9, diperoleh setengah nilai signifikansi yaitu 0,003. Nilai tersebut lebih kecil dari 0,05, maka $\mathrm{H}_{0}$ ditolak. Dengan demikian dapat disimpulkan bahwa Peningkatan kemampuan penalaran matematis siswa melalui penerapan teori belajar Van Hiele berbantuan Geogebra lebih baik daripada siswa yang belajar dengan menggunakan pembelajaran ekspositori.

Selain untuk mengetahui peningkatan kemampuan penalaran matematis, penelitian ini juga dilakukan untuk mengetahui bagaimana sikap siswa terhadap pembelajaran yang menerapkan teori belajar Van Hiele berbantuan Geogebra, berikut adalah hasil analisis yang telah dilakukan berdasarkan perhitungan angket.

Tabel 10. Persentase Sikap Siswa Secara Keseluruhan

\begin{tabular}{cccc}
\hline \multirow{2}{*}{ Indikator } & \multicolumn{2}{c}{ Rata-rata Persentase } & \\
\cline { 2 - 3 } & $\begin{array}{c}\text { Sikap } \\
\text { Positif }\end{array}$ & $\begin{array}{c}\text { Sikap } \\
\text { Negatif }\end{array}$ & Keterangan \\
\hline 1 & $85,71 \%$ & $14,29 \%$ & Hampir Seluruhnya Positif \\
\hline 2 & $89,95 \%$ & $10,05 \%$ & Hampir Seluruhnya Positif \\
\hline 3 & $93,21 \%$ & $6,79 \%$ & Hampir Seluruhnya Positif \\
\hline Rata-rata (\%) & $89,62 \%$ & $10,38 \%$ & Hampir Seluruhnya Positif \\
\hline
\end{tabular}

Berdasarkan Tabel 10 diatas, dapat dilihat bahwa rata-rata sikap siswa positif terhadap indikator pertama yaitu terhadap pebelajaran yang menggunakan teori belajar Van Hiele dengan persentase sebesar $85,71 \%$. Pada indikator kedua yaitu sikap siswa terhadap Software Geogebra rata-rata sikap siswa juga positif yaitu dengan persentase sebesar 89,95\% dan 93,21\% pada indikator ketiga yaitu sikap siswa terhadap soal-soal kemampuan penalaran matematis.

Dilihat dari beberapa penjelasan diatas maka dapat disimpulkan bahwa sikap siswa terhadap pembelajaran yang menerapkan teori belajar Van Hiele berbantuan Software Geogebra adalah positif. 


\section{KESIMPULAN}

Berdasarkan hasl pengukuran, pengamatan, dan analisis data yang diperoleh selama penelitian pembelajaran matematika dengan menerapkan teori belajar Van Hiele berbantuan Geogebra, maka peneliti mendapatkan beberapa kesimpulan bahwa peningkatan kemampuan penalaran matematis siswa yang belajar dengan menggunakan teori Van Hiele beberbantuan GeoGebra lebih baik daripada siswa yang belajar dengan menggunakan pembelajaran ekspositori dan pada umumnya sikap siswa terhadap pembelajaran yang menerapkan teori belajar Van Hiele berbantuan Geogebra adalah positif.

\section{REFERENSI}

Komala, E., \& Rismayanti, R. (2017). Penerapan Pendekatan Explicit Instruction dengan Teknik Scaffolding untuk Meningkatkan Kemampuan Penalaran Matematis Siswa Smp. PRISMA, 6(2). https://doi.org/10.35194/jp.v6i2.65

Maskur, R., Sumarno, Rahmawati, Y., Pradana, K., Syazali, M., Septian, A., \& Palupi, E. K. (2020). The effectiveness of problem based learning and aptitude treatment interaction in improving mathematical creative thinking skills on curriculum 2013. European Journal of Educational Research, 9(1), 375-383. https://doi.org/10.12973/eu-jer.9.1.375

Monariska, E. (2018). Upaya Meningkatkan Kemampuan Penalaran Matematis Siswa SMK melalui Pembelajaran Kooperatif Tipe Numbered Head Together. PRISMA, 7(2), 217. https://doi.org/10.35194/jp.v7i2.531

Muhammad, G. M. (2017). Analisis Kemampuan Penalaran Matematis Mahasiswa pada Mata Kuliah Struktur Aljabar II (Teori Gelanggang). PRISMA, 6(1). https://doi.org/10.35194/jp.v6i1.29

Nanang Supriadi. (2015). Pembelajaran Geometri Berbasisgeogebra sebagai Upaya Meningkatkan Kemampuan Komunikasi Matematis Siswa Madrasah Tsanawiyah (MTs). Al-Jabar: Jurnal Pendidikan Matematika, 6(2), 1-14.

Salmina, M., \& Nisa, S. K. (2018). Kemampuan Penalaran Matematis Siswa Berdasarkan Gender Pada Materi Geometri. Jurnal Numeracy, 5(1), 41-48.

Septian, A. (2017). Penerapan Geogebra untuk Meningkatkan Kemampuan Pemecahan Masalah Matematis Mahasiswa Program Studi Pendidikan Matematika Universitas Suryakancana. PRISMA, 6(2). https://doi.org/10.35194/jp.v6i2.212

Septian, A., \& Komala, E. (2019). Kemampuan Koneksi Matematik dan Motivasi Belajar Siswa dengan Mengunakan Model Problem-Based Learning (PBL) Berbantuan Geogebra di SMP. PRISMA, 8(1), 1-13. https://doi.org/10.35194/jp.v8i1.438 Suherman, N. (2016). Upaya Meningkatkan Kemampuan Berpikir Geometri Van Hiele Siswa SMP Melalui Model Pembelajaran Example Non Examples. Jurnal Analisa, 2(2), 69-80. https://doi.org/10.15575/ja.v2i2.5379

Tina Sri Sumartini. (2015). Peningkatan Kemampuan Penalaran Matematis Siswa melalui Pembelajaran Berbasis Masalah. Jurnal Pendidikan Matematika, 5(1), 1-10.

Zengin, Y., Furkan, H., \& Kutluca, T. (2012). The effect of dynamic mathematics software geogebra on student achievement in teaching of trigonometry. Procedia - Social and Behavioral Sciences. https://doi.org/10.1016/j.sbspro.2011.12.038 
Zyngier, D., Zullig, K. J., Collins, R., Ghani, N., Hunter, A. A., Patton, J. M., ... 김성식. (2013). PISA 2012 results : ready to learn. Students' engagement, drive and selfbeliefs (volume III). School Effectiveness and School Improvement, 24(2), 520 pages. https://doi.org/10.1080/09243453.2012.680892 